\title{
WAYS TO ORGANIZE NATIONAL MOVEMENT GAMES IN DIFFERENT BRANCHES OF THE PHYSICAL CULTURE MOVEMENT
}

\author{
Kutlimurotov Mukhammeddin Amangeldi uli \\ teacher of Nukus branch of Nukus branch of the Uzbek State University of Physical Culture and Sports
}

\begin{abstract}
The decrees and resolutions adopted by the President and the government of the Republic of Uzbekistan provide for the health, physical culture and sports expansion, the creation of conditions and the active participation increase in the settlements with the participation of specialists. The main purpose of this is to protect the population health, to develop physical and spiritual wellbeing.
\end{abstract}

Keywords:

physical education, sports, youth, student, hope, harmonious generation, universiade, hook, trap, spinning the ball, potato planting, Alpomish games, Tomaris games, endurance.

Article Received: 18 October 2020, Revised: 3 November 2020, Accepted: 24 December 2020

There are government agencies and public organizations that manage and represent the physical education movement. They are mainly officials of the Ministry of Culture and Sports of the Republic of Uzbekistan, officials of the Office of the President of the Republic, officials of the Government of the Republic, physical culture and sports departments of almost all ministries. The organizers of the community are trade unions, the youth movement, the Women's Committee, charitable foundations and others. Dynamo, Yoshlik, Talaba, Pakhtakor sports clubs, Vatanparvar organization, Trade Union Sports Society, Central military sports club (CMSC) and sports clubs under a number of government agencies conduct physical culture and sports activities. The link has provincial, city, and district flags. These sports organizations and associations are youth ("Youth"), students ("Student"), workers (Trade Union Sports Society, "Pakhtakor" sports club), the military (MDSC), police officers ("Dynamo") and etc. organizes representatives of various similar industries. The main goals and objectives of these organizations are to engage the public in physical culture and sports, to hold various competitions, to prepare and participate in international sports competitions by organizing various teams. It also promotes the use of national movement games in public health events, various sports festivals and competitions, and exhibition sports systems. The main role of each sports organization and association is to hold the event in public. For example, they celebrate Navruz, Independence Day, harvest holidays, and professional days by using multi-stage, movement games that organize various sports competitions in teams. All ministries and public organizations cooperate in the organization of multi-stage sports competitions (Umid Nihollari, Barkamol Avlod, Universiade), national competitions of national games. A variety of action games will be on display at the opening and closing ceremonies of these events. In particular, the elements of our national wrestling, equestrian games, tug-of-war, wrist strength testing, and other national movement games have a deep place in the content of the demonstration. At republican festivals such as "Alpomish Games" and "Tomaris Games", the main content of the program is animated games. It is also worth noting that it has become a tradition to organize a variety of action games at large weddings in villages, castles (settlements) with the participation of employees of the lower branches of the sports club "Pakhtakor". This includes shoulder-to-shoulder shooting and wrist-fitness sports. Public health and sports facilities can be divided into the following types: 1. Sports facilities. 2. Summer vacations for schoolchildren. 
3. Health and sports facilities for schoolchildren and students. 4. Holiday homes for workers and intellectuals. 5. Special rehabilitation centers. 6 . Medical institutions. It is known that in their work, the main goals and objectives of the process of rehabilitation, physical development and exercise in various ways. Wellness activities at sports facilities will also be different: health group trainings, mass physical and cultural events on the occasion of a day off or various holidays (preparation for special tests, competitions between departments, workshops or teams, individual training, family training, exercises etc.) Special fitness groups are set up with people whose health has deteriorated for a variety of reasons (severe pain, weight loss, etc.) or who are aiming for physical activity. Depending on the type of group, the people in it are engaged in special exercises and movement games. At such times, the movements of the neck, shoulders, arms, torso, and legs, as well as the movements of the neck, shoulders, arms, legs, etc., are performed by counting or by time. Also, action games like "Empty" and "From bag" can be fun for participants. Active games play an important role in the health activities of secondary school students, such as trips to summer camps, various competitions, swimming in running water. Especially in shady and cool places, where the field is rich in meadows and natural landscapes, moving games, relay races give good results. At such times, national movement and various relay games such as "Rain", "From bag", "Hook", "Battle of the Roosters", "Rabbit without home" will be important in purpose and content. In explaining, organizing, conducting, and completing the games, the organizer, the physical education teacher, uses all the methods of pedagogical principles. Health and sports facilities for schoolchildren and students are organized in mountainous areas or on river banks, such as summer camps for schoolchildren. It should be noted that the health and sports facilities of many professional colleges and universities have advanced experience. In particular, in the sports camps of Tashkent state pedagogical university named after Nizami (Khumson), UzUWL (Kumushkon), Samarkand state university (Urgut), Fergana state university (KhamzabodShokhimardon) sports competitions, friendly matches, championships in sports In particular, in addition to events such as one-day and multi-day (2-3) hiking trips, shelling (targeting), there will be interesting discussions on various relays, various action games. They are mainly interested in milhy and modern action games, such as "Find the ball", "Pull on the rope", "Who will climb to the top faster", "Herd ball" and "Chillik". Therefore, in addition to physical qualities, aesthetic pleasure is a priority for practitioners and spectators. Holiday homes for workers and intellectuals are located in mountainous areas, where national cultural events are regularly organized. Action games also have a special place in the content of the link. Especially as a group, as a team, various games and relays are used more often. Games such as tennis, badminton, hand volleyball, volleyball, kicking the ball over the tennis net, and head-to-head are fun activities. Action games such as jumping rope in the fields, running through the hoops, pulling sticks, ropes, hanging on a tree (tumik) and other natural objects (stairs), pulling, hanging on the hands, shooting also applies. Interestingly, games such as "Third is over", "Hook", "Trap", "Rotate the ball in a circle", "Planting potatoes" are used purposefully. It is known that in mountain resorts there are competitions in hiking, swimming, splashing, as well as movement games, such as jumping over ditches, canyons and obstacles. At the end of the holiday there will be action games such as bonfires, debates, arguments, riddles. People, young and old, who are happy with the health activities, share their impressions and offer active games and trips in a more meaningful and interesting way. In general, physical culture activities, especially movement games, and hiking are more important in terms of purpose and content in the health and recreation of workers. Rehabilitation facilities are mainly saunas designed to improve the health and fitness of various institutions and employees. They will 
have a steam bath, cold pools, massage rooms and exercise equipment. People, first of all, perform various exercises on the advice of experts. Football and other playgrounds, sports facilities with gyms or close to saunas, usually have elements of sports games such as football (volleyball, basketball, tennis, badminton) will compete. Others compete with each other in various relays, such as hanging, pulling, hanging, and wrist strength testing. In relay races, members of the body, especially the joints, exercise to increase muscle strength and endurance. They run on time on special devices (bicycles, rotating rubber tracks, etc.) to strengthen the joints and muscles of the legs, and argue about trying. The balconies of multi-storey houses, as well as the courtyards are equipped with sports equipment such as horizontal bars, dumbbells, boxing equipment, various stuffed balls, ropes, gymnastic sticks, and the number of home users is growing. And for some as a family, they have become accustomed to working out at home. In short, the use of special health facilities and mobile games at home can be a factor in staying physically fit. This is important in living a healthy lifestyle. When we say medical institutions, we mean not only hospitals polyclinics, sanatoriums, and private medical facilities also serve as specific health facilities along the way. The structure of such places is divided into the following types: 1. Exercise therapy in hospitals. 2. Treatment through physical education in polyclinics. 3 . Exercise and movement therapy in holiday homes and sanatoriums.4. Use of physical exercises in permanent (inpatient) special medical institutions (hospitals, sanatoriums, etc.). It should be noted that the treatment with physical education facilities (movement games) in these institutions is carried out mainly by specialized physical education specialists. Those who feel well and feel a positive change can do the exercises independently with the permission and advice of the coaches. The use of exercise in hospitals is mainly done in groups with patients with colds and mild illnesses. Severely bruised, broken, dislocated bones, exercises that improve muscle movement (bending, writing, rotating, pulling, pushing, etc.) are performed in the form of games. Patients who are recovering from major surgery also need a certain amount of play and exercise. Polyclinics, rest homes and sanatoriums hold various games depending on the physical condition of the people. The simulators include exercise, massage, and cold water (baths and pressurized water). People who are physically fit and healthy are advised to participate in competitions with elements of sports such as football, volleyball, tennis, badminton, gymnastics, athletics (running, running, jumping, throwing), swimming. Special movement games (chasing, pushing, "trap", jumping, "fishing rod", "excess", "blindfolding", etc.) are organized separately and performed in public. As a result, vacationers are able to ensure that the participants have fun, have a meaningful rest and, most importantly, are physically fit. Students and young people in the field of physical education should have a deeper understanding of special subjects in the educational process, such as physical therapy (medical physical education). They need to develop relevant skills and acquire the necessary practical skills during the internship process. This is due to the fact that in the organization of physical education games in educational and recreational areas of workers, it is necessary to provide first aid and, if necessary, to organize movement games in a variety of public health activities. In short, the use of exercise in medical institutions is primarily aimed at cure, work and recovery in life.

Residential settlements are mainly understood as cities and villages. Villages, in turn, consist of fortresses (settlement), large and small villages. Cities, neighborhoods, neighborhoods are different. Currently, sports facilities (football fields, various playgrounds, indoor and outdoor swimming pools, special trainers, etc.) are being built in large villages, fortresses, city neighborhoods. The decrees and resolutions adopted by the President and the government of the Republic provide for the population rehabilitation with the participation of specialists, 
the physical culture and sports expansion, the creation of conditions and the active organizers increase. The main purpose of this is to protect the health of the population, to develop physical and spiritual well-being. This requires the involvement of the general public in the organization of mass sports competitions in various sports, prestigious events on mobile games with national values. Due to independence, the construction of various office buildings in cities and villages, the expansion of playgrounds for cultural events, and especially the construction of multi-storey houses and modern courtyards are on the rise. This, in turn, indicates that people's culture of life is improving. And the growth of the culture of marriage encourages healthy living. Sports and physical activity play an important role in a healthy lifestyle. In the context of courtyards and multi-storey houses, there are more and more people who are aiming to improve their health through family and independent, individual exercise. Spacious playgrounds, children's playgrounds, and alleys are busy with a variety of games throughout the day, especially on weekends, holidays, and holidays. Parents, community members and professionals are involved in organizing this. Large weddings in rural areas, traditional holidays and other cultural events include wrestling, horse games, and various national movement games between adults and children. Especially popular among girls and boys are national movement games such as "Chase", "Tug of war", "Wrestling on the shoulder", "Pedestrian", "Nine heads", «" put Bota " », « Blindfold », « Who stayed ». Children and teenagers enjoy playing fencing, horseback riding, shooting games on donkeys and horses in the hills, as well as developing their physical maturity. Roosters, rams, dog fights, sparrows and quails singing (arguing), old women and old people talking, dancing, various movement games continue to be demonstrated as ancient national games. They serve as a cultural heritage for aesthetic pleasure and longevity. In Tashkent city, regional centers, district centers, large fortresses (townships) mass health-improving events are organized on a large scale. Relay games and national action games are widely used, especially in neighborhoods and multi-storey housing estates.

\section{REFERENCES}

[1] Usmonkhojayev TS, Khojayev F. Moving games. T., 1992.

[2] Usmonkhojayev TS, Meliyev H. National action games. 2000.

[3] Khojayev F., Rahimkulov K.D., Nigmanov B.B. Methods of teaching sports and movement games. 2008.

[4] Kosimov A.Sh. Moving games. 1983.

[5] Normurodov A.N. Uzbek national games. T., 1999.

[6] Usmonkhojayev T.S., Khojayev F. 1001 games. T., 1990

[7] Khabibullaev SH, Khudoiberganov JS Special exercises for the development of physical qualities. Subscribe to the scientificmethodical magazine "Teacher and Continuing Education"! "Teacher and Continuing Education". 2020.143-147

[8] Mamatqulov R.S. Education of students' physical qualities in pedagogical universities using the cluster method using badminton Material of the XVI International Scientific and Practical Conference Strategic Issues of World Science -202007-15 Iutego 2020 RokuVolume 11 2-8 p.

[9] Mamatqulov R.S. The role of chess in the education of preschool children "TEACHER AND CONTINUOUS EDUCATION” №1-1 Nukus - 2020.151-156 p

[10] Khudoiberganov JS Ways of education in sports and education of its features (on the example of sports games). Teacher and Continuing Education Scientific Methodological Journal 2020

[11] Khudoyberganov J.S. Special exercises to develop physical qualities. Teacher and Continuing Education Scientific Methodological Journal 2020

[12] Khudoiberganov J.S. Education and its features in sports. Scientific and practical 
research in Uzbekistan. Republican scientificpractical conference 2 pages. Tashkent - 2020

[13] Khudoiberganov J.S. Physical endurance in studentsEducation and technology Collection of scientific and methodical articles 2 pages Part 2 Tashkent 2020

[14] Khudoiberganov J.S. Methods of improving the technical and tactical skills of wrestlers. « Republican online scientific-practical conference "Global Perspectives on Physical Culture and Sports: Problems and Solutions" 5 pages Nukus 2020 